\title{
NÍVEL DE ESTRESSE DA EQUIPE DE ENFERMAGEM DE UM HOSPITAL DE PEQUENO PORTE NO INTERIOR DO ESTADO DE GOIÁS.
}

STRESS LEVEL OF NURSING TEAM OF A SMALL HOSPITAL IN THE STATE OF GOIÁS.

\section{Milce Costa}

Docente do curso de Farmácia/Enfermagem da FACER- Unidade Ceres. Doutora em Medicina Tropical UFG. milcebiomol@yahoo.com.br Av. Brasil, S/N, Qd. 13 Morada Verde Ceres - Go. CEP: 76.300-000.

\section{Viviane Rodrigues Tavares}

Docente do curso de Farmácia/Enfermagem da FACER- Unidade Ceres. Mestre em Enfermagem UFG. vianevivi@ hotmail.com Av. Brasil, S/N, Qd. 13 Morada Verde Ceres - Go. CEP: 76.300000 .

\section{Cleudinéia Pereira da Silva}

Acadêmica do Curso de Enfermagem da FACER- Faculdade de Ceres-GO: didicleu@hotmail.com

\section{Fabiana Ramos Leite}

Acadêmica do Curso de Enfermagem da FACER- Faculdade de Ceres-GO: fabianabiabibi@hotmail.com

\section{Lia Pinto Cunha Borges Dos Santos}

Acadêmica do Curso de Enfermagem da FACER- Faculdade de Ceres-GO: liapcbs@ hotmail.com

\section{Camila Regina Pouças Marinho}

Acadêmica do Curso de Enfermagem da FACER- Faculdade de Ceres-GO: camiladoalem@ hotmail.com 


\section{RESUMO}

Introdução: A Organização Internacional do Trabalho (OIT) reconhece que praticamente todas as profissões sofrem de estresse, porém, a enfermagem é apontada como uma das mais estressantes, sendo, por isso, alvo de estudos. Objetivo: Este estudo teve como objetivo avaliar o nível de estresse destacando os principais sintomas do estresse em enfermeiros e técnicos de enfermagem que atuam em um hospital de pequeno porte no interior do estado de Goiás. Metodologia: Foram incluídos neste estudo 36 profissionais da equipe de enfermagem (12 enfermeiros e 24 técnicos de enfermagem) que atuam em um Hospital de pequeno porte no interior do estado de Goiás. O instrumento utilizado para coleta de dados foi um questionário padronizado e auto aplicável que evidencia os principais fatores e fontes de estresse no ambiente hospitalar. Resultados e discussão: Os resultados demonstraram que 36,3\% dos profissionais participantes apresentam estresse, deste percentual, 83,3\% encontram-se na fase de resistência e $16,7 \%$ na fase de exaustão. O percentual de $63,6 \%$ da equipe pesquisada que não apresentou estresse deixa claro que, possivelmente, mesmo que a equipe conviva com inúmeros estressores, estes não interferem de maneira significativa na vida profissional e pessoal do indivíduo. Conclusão: O baixo percentual de estresse provavelmente se deva ao conjunto de situações favoráveis ao bem estar do profissional, tanto no ambiente externo quanto no próprio ambiente de trabalho.

Palavras-chave: estresse, enfermagem, hospital, equipe de enfermagem.

\section{ABSTRACT}

Introduction The International Labour Organization (ILO) admits that virtually all professions suffer from stress. However, nursing is considered one of the most stressful, and because of this, it is the target of a lot of research. Goal This study has as main goal to evaluate the stress level, the main sources, factors that cause stress and even its symptoms in nurses and nursing technicians who work in a small hospital in the state of Goiás. Methodology Were included in this study 36 professional nursing staff (12 nurses and 24 nursing technicians) orking in a small hospital in the state of Goiás. The instrument used for data collection was a standardized questionnaire and self applicable questionnaire which shows the main factors and sources of stress in the hospital environment. Results and discussion Our results showed that only $36.3 \%$ of 
participants have professional stress; in this percentage, $83.3 \%$ are found in the process of resistance and $16.7 \%$ at the stage of exhaustion. The considerable percentage of $63.3 \%$ of the team questioned that did not show stress makes it clear that even if the team is with many sources stressful, they do not interfere significantly in their professional and personal lives. Conclusion The low percentage of stress is due probably to the set of favorable conditions to the welfare of the professional, both in the external environment, and into their workplace.

Keywords: stress, nursing, hospital, nursing staff

\section{Endereço para correspondência}

Av. Brasil, S/N, Qd. 13 Morada Verde Ceres - Go. CEP: 76.300-000. milcebiomol@yahoo.com.br

\section{INTRODUÇÃO}

Segundo dados da Organização Mundial de Saúde, $90 \%$ da população mundial é afetada pelo estresse, tomando aspectos de uma epidemia global (BATISTA \& BIANCHI, 2006).

$\mathrm{O}$ estímulo estressor pode desencadear diferentes respostas em diferentes organismos, ou seja, diferentes pessoas podem reagir a um mesmo estressor de maneira diferente. A capacidade de lidar com os eventos estressores podem variar conforme a herança genética, estilo de vida, experiência de aprendizado adquirida durante a vida e dependendo da estratégia de enfrentamento utilizada pelo indivíduo. O estímulo do agente estressor pode se transformar num estresse positivo ou negativo. O estresse de natureza positiva é denominado "Eustress", nesta situação a pessoa tenciona-se, atingindo um nível ideal de esforço e é realimentada por resultados positivos. O termo "Distress" por sua vez, caracteriza o estresse negativo e está relacionado à sobrecarga no qual ocorre a ativação crônica e repetida do eixo hipotálamo-hipófise-adrenal (HHA), onde ocorre a constante elevação dos hormônios originando algumas alterações patológicas (MURTA \& TRÓCCOLI, 2004).

Os estressores no ambiente de trabalho podem ser classificados em três fatores: físicos, sociais e emocionais. Os fatores estressores físicos estão relacionados normalmente à 
sobrecarga de trabalho, causada pela designação de muitas tarefas com prazos curtos para sua execução, ao ambiente insalubre, à ambiguidade de prioridades e ao nível de autoridade e de autonomia impostos ao indivíduo. Já os fatores estressores sociais, referem-se à tensão que o ser humano pode sentir em virtude de seus contatos com outras pessoas quando ele necessita interagir de modo a expressar algum tipo de sentimento, positivo ou negativo, ou expressar algum desejo ou reivindicar seus direitos. O estresse emocional por sua vez, está relacionado com situações como ter que lidar com a morte, que provoca na equipe de enfermagem sentimento de tristeza, dor e sensação de fracasso; lidar com as angústias dos familiares dos pacientes, além disso, a comunicação do óbito para a família também se configura em uma tarefa difícil (LIPP, 2002; MOLINA \& GUIMARÃES, 2007).

A Organização Internacional do Trabalho (OIT) reconhece que praticamente todas as profissões padecem de estresse, porém, a enfermagem é apontada como uma das mais estressantes, sendo, por isso, alvo de estudos. Os enfermeiros encontram-se expostos a riscos de natureza física, química e biológica, o que justifica a inclusão da profissão no grupo das profissões mais estressantes. De acordo com Silva et al., 2008, os riscos físicos se referem aos ruídos, vibrações, radiações ionizantes e não ionizantes, temperaturas extremas, pressões anormais e umidades, iluminação inadequada e exposição a incêndios e choques elétricos. Os riscos químicos por sua vez, dizem respeito ao manuseio de gases e vapores anestésicos, antissépticos, esterilizantes e poeiras. Os riscos biológicos estão relacionados aos microrganismos como bactérias, fungos, protozoários, vírus e material infecto-contagioso presentes no dia-a-dia deste profissional. É importante ainda relatar que existem alguns riscos menos discutidos entre os profissionais, como os ergonômicos e os psicossociais. Os riscos ergonômicos compreendem o local inadequado de trabalho, levantamento e transporte de pesos, postura inadequada, erro de concepção de rotinas e serviços, mobiliários. Já os riscos psicossociais, advêm da sobrecarga vinda do contato com os sofrimentos dos pacientes, como a dor e a morte, o trabalho noturno, rodízios de turno, jornadas duplas e até triplas de trabalho, ritmo acelerado e tarefas fragmentadas e repetitivas (MARZIALE \& RODRIGUES, 2002).

Dentre os riscos citados pode-se concluir que características do trabalho como atuar em vários turnos, carga horária excessiva e jornada fatigante são extremamente exaustivos e muitos profissionais chegam há trabalhar 60 horas por semana devido à realização de horas extras, seqüências de plantões ou ao acúmulo de empregos (HAAG, 2000 apud LOPES, 2001). 
Alguns autores apontam que o desgaste físico do profissional de enfermagem se deve principalmente à manipulação e transporte do paciente, auxiliado por macas e cadeiras de rodas, seu deslocamento para realização de exames e as rotinas de higienização. Neste contexto, as rotinas de desinfecção e esterilização de materiais contaminados, manejo, reposição de materiais, acelerado ritmo de trabalho e uma gama de outros procedimentos comuns no dia-a-dia da enfermagem causam ao profissional cansaço, dores no corpo e desânimo, favorecendo o aparecimento de doenças ocupacionais e acidentes no trabalho (RIBEIRO \& SHIMIZU, 2007; LEITE et al.,2007). Além disso, a enfermagem enfrenta uma sobrecarga de trabalho tanto quantitativa, evidenciada pela responsabilidade por mais de um setor hospitalar, quanto qualitativa, verificada na complexidade das relações humanas, por exemplo, enfermeiro/cliente, enfermeiro/profissional de saúde; enfermeiro/ familiares (MONTANHOLI et al., 2006).

Os riscos da profissão, a sobrecarga de trabalho e suas conseqüências vivenciadas pelo profissional de enfermagem, tornam o desafio maior quando este profissional é do sexo feminino. De uma maneira geral, Spindola (2000) relata que o serviço de enfermagem é composto na maioria das vezes por mulheres e que os múltiplos papéis assumidos podem conduzir a trabalhadora de enfermagem muito rapidamente ao estado de estresse considerando que sua inserção no mercado de trabalho não a desvincula das tarefas domésticas e da educação dos filhos, resultando num acúmulo de atribuições.

Uma vez que a enfermagem é considerada uma profissão altamente estressante (BATEMAN \& STRASSER, 2000), julga-se importante investigar o estresse dos trabalhadores desta área. Desta forma, acreditamos ser de fundamental importância tratar de temas que abordam a saúde do trabalhador, principalmente quando este possui como centro do seu processo laboral lidar com a saúde/doença da população Segundo dados do Conselho Federal de Enfermagem (COFEN, 2011), os trabalhadores de enfermagem no Brasil constituem a maior categoria da força de trabalho em saúde (cerca de 35\%). Apesar deste elevado contingente não existem dados estatísticos claros sobre os problemas de saúde que acometem os trabalhadores de enfermagem.

Desta forma, este estudo pretende avaliar o nível de estresse e as fontes geradoras de estresse em enfermeiros e técnicos de enfermagem que atuam num Hospital de pequeno porte no interior do estado de Goiás.

\section{METODOLOGIA}


Tratou-se de um estudo quantitativo-exploratório e descritivo. A pesquisa realizou-se num Hospital de pequeno porte no interior do estado de Goiás, Centro de atenção à saúde de média complexidade, com atendimento exclusivo ao Sistema Único de Saúde (SUS). O referido hospital disponibiliza 33 leitos de internação, presta serviços em diversas especialidades, com média de ocupação de $95 \%$ dos leitos, com permanência de no mínimo cinco dias. Possui um corpo clínico com 12 médicos. Os dados foram coletados nos meses de agosto e setembro de 2011, entre os profissionais da equipe de enfermagem que atuam em um Hospital de pequeno porte no interior do estado de Goiás. Foram incluídos neste estudo 36 profissionais da equipe de enfermagem, sendo 12 enfermeiros e 24 técnicos de enfermagem. Tais profissionais trabalham em turnos alternados, diurnos, noturnos e plantões, distribuídos nos setores de pequenas cirurgias, enfermarias femininas, masculinas, pediátricas e ambulatório 24 horas. Dentre os critérios de inclusão dos participantes deste estudo foi determinado somente para os profissionais de enfermagem que fizessem parte da escala mensal de trabalho do hospital no período em que a coleta de dados foi realizada. Além disso, o participante obteve esclarecimento sobre o objetivo da pesquisa e seu anonimato, bem como outros esclarecimentos, através do Termo de Consentimento Livre e Esclarecido, o qual foi devidamente assinado pelo profissional que concordou em participar desta pesquisa. Foram excluidos os profissionais que estavam de férias ou que faltaram à escala de trabalho no período em que ocorreu a coleta de dados.

Após a concordância do profissional em participar da pesquisa, os questionários foram entregues pessoalmente às equipes de enfermagem nos dois turnos, em envelopes lacrados. O profissional levou o envelope para casa e o devolveu em dois dias à chefia da enfermagem, também lacrado, preenchido ou não, segundo sua disposição em participar da pesquisa, quando então foram recolhidos pelas pesquisadoras. Foi utilizado como instrumento para coleta de dados um questionário padronizado e auto aplicável que evidencia os principais fatores e fontes de estresse no ambiente hospitalar. O questinário aplicado ao enfermeiro foi diferente do aplicado ao técnico de enfermagem, devido à diferença na atuação profissional. Foram utilizados como referência para a sua construção, os instrumentos adotados por FERNANDES, 1997; LAUTERT et al., 1999 e LIPP \& GUEVARA, 1994. Composto das seguintes partes: 
1- Dados de identificação - esta parte é composta por questões direcionadas ao mapeamento sócio demográficos e profissional dos participantes, tais como: gênero, idade, tempo de trabalho na profissão, jornada de trabalho e número de filhos.

2- Fontes de Estresse aplicado ao técnico de enfermagem - nesta parte do questionário foram analisadas as fontes geradoras de estresse a partir das condições de trabalho. Nesse sentido, as questões fazem parte do item que avalia esta categoria no Job Diagnostic Survey - JDS, utilizado por Fernandes (1997). A partir do instrumento original, foram feitas algumas adaptações pelas pesquisadoras, com a finalidade de adequação dos itens às características da população participante da pesquisa. Por exemplo, os itens de 15 a 23 do instrumento foram sugeridos pelas pesquisadoras.

3- Fontes de Estresse aplicado ao enfermeiro - nesta parte do questionário foram analisadas as fontes geradoras de estresse a partir das condições de trabalho. Nesse sentido, as questões fazem parte do item que avalia esta categoria no Instrumento de coleta de dados, pesquisa sobre o estresse na atividade gerencial do enfermeiro de hospital, Porto Alegre (RS), Brasil, utilizado por Lautert et al., 1999.

4 - Aspectos relacionados às condições de trabalho - Esta parte apresenta questões que investigam os sentimentos dos profissionais de enfermagem em relação a algumas condições de trabalho (Lautert et al., 1999). Os itens de 6 a 9 do instrumento foram sugeridos pelas pesquisadoras.

5- Inventário de Sintomas de Stress - I.S.S.L (LIPP \& GUEVARA, 1994) - o I.S.S.L é um teste aprovado pelo Conselho Federal de Psicologia, útil na identificação de quadros característicos de estresse, possibilitando diagnosticar o estresse em adultos e as fases em que se encontra (fase de alerta, fase de resisência, fase de quase-fase exaustão e fase de exaustão). Baseia-se em um modelo quadrifásico e propõe um método de avaliação de etresse que enfatiza a sintomatologia somática e psicológica etiologicamente a ele ligada através de 3 quadros: Quadro 1: composto de 15 itens. Refere-se aos sintomas físicos ou psicológicos que a pessoa tenha experimentado nas últimas 24 horas. Corresponde à fase de alerta do estresse, a pessoa que 
manisfestar sete ( 7 )ou mais sintomas. Quadro 2: O segundo, composto de dez sintomas físicos e cinco psicológicos, experimentados na última semana. Corresponde à fase de resistência ou quase-exaustão do estresse, a pessoa que manisfestar quatro ( 4 )ou mais sintomas. Quadro 3: E o terceiro quadro, composto de 12 sintomas físicos e 11 psicológicos destina-se em levantar os sintomas experimentados no último mês e corresponde à fase excessiva do estresse, denominada exaustão, a pessoa que manisfestar nove ( 9 )ou mais sintomas. No total, o ISSL apresenta 37 itens de natureza somática e 19 psicológicas, sendo os sintomas muitas vezes repetidos, diferindo somente em sua intensidade e seriedade.

Assim os dados extraídos a partir do instrumento de coleta, foram analisados quantitativamante, organizados no Micro Soft Excel para a obtenção dos resultados em forma de figuras, e por análise estatística descritiva. Foram contemplados os aspectos éticos desta pesquisa tomando-se por base os itens III. 3.i, III. 3.t e IV das Diretrizes e Normas Regulamentadoras de Pesquisas envolvendo Seres Humanos - Resolução do Conselho Nacional de Saúde (CNS) 196/96. O presente estudo foi aprovado pelo Comitê de Ética em Pesquisa, sob protocolo de número: $518.812(31 / 01 / 2014)$.

\section{RESULTADOS E DISCUSSÃO}

\section{DISTRIBUIÇÃO DO NÚMERO DE PROFISSIONAIS}

Da população de 36 (100\%) profissionais de enfermagem atuantes na unidade hospitalar em estudo, participaram da pesquisa 33 (91,7\%). Sendo que, todos os profissionais pesquisados estão regulamentados pelo COFEN (2006). De acordo com os critérios de seleção estabelecidos, dois enfermeiros foram excluídos, pois não entregaram o questionário na data estabelecida pelas pesquisadoras. Dos 24 (100\%) técnicos de enfermagem pesquisados, um $(4,2 \%)$ foi excluído da pesquisa pelo mesmo motivo descrito anteriormente.

Pelo número de questionários que retornaram preenchidos, 33 (91,7\%), notou-se uma excelente disposição para participação da pesquisa de boa parte da equipe de enfermagem do hospital. Assim sendo, o questionário foi aplicado a 33 profissionais de enfermagem, sendo 23 técnicos de enfermagem e 10 enfermeiros, conforme mostra a Tabela 1. 
TABELA 1: Distribuição do número de profissionais de enfermagem num hospital de pequeno porte no interior do estado de Goiás - 2011

\begin{tabular}{lccc} 
Profissionais & População & \multicolumn{2}{c}{ Sujeitos pesquisados } \\
\hline & $\mathrm{N}$ & $\mathrm{N}^{\mathbf{0}}$ & $\%$ \\
Enfermeiros & 12 & 10 & 83,3 \\
Técnicos de enfermagem & 24 & 23 & 95,8 \\
TOTAL & $\mathbf{3 6}$ & $\mathbf{3 3}$ & $\mathbf{9 1 , 7}$ \\
\hline
\end{tabular}

VARIÁVEIS DOS SUJEITOS DO ESTUDO SEGUNDO GÊNERO, IDADE, NÚMERO DE FILHOS, CARGA HORÁRIA DIÁRIA, TEMPO DE TRABALHO NA PROFISSÃO

Os resultados a seguir estão apresentados pelos dados de identificação com questões direcionadas ao mapeamento sócio-demográfico e profissional dos participantes, conforme mostra a Tabela 2 .

A análise das variáveis sócio-demográficas, em relação ao gênero, demonstrou tratarse de uma população predominantemente feminina, tanto entre enfermeiros (80\%) quanto em técnicos de enfermagem (86,9\%), enquanto o gênero masculino representou (20\%) entre a população de enfermeiros e $(13,1 \%)$ entre os técnicos de enfermagem.

TABELA 2: Distribuição da população, segundo variáveis quantitativas - profissionais de enfermagem num hospital de pequeno porte no interior do estado de Goiás - 2011.

Amostra / N =10 Enfermeiros e N = 23 Técnicos de Enfermagem

\begin{tabular}{lcccc}
\hline \hline VARIÁVEIS & \multicolumn{2}{c}{ Enfermeiro (a) } & \multicolumn{2}{c}{ Técnico (a) de Enfermagem } \\
Gênero & $\mathrm{N}$ & $\%$ & $\mathrm{~N}$ & $\%$ \\
Feminino & & & & \\
& 8 & 80 & 20 & 86,9
\end{tabular}


Masculino

Idade (anos)

$20-30$

$30-40$

$40-50$

$50-60$

$\mathbf{N}^{\mathbf{0}}$ de Filhos

0

1

2

3

4

Carga horária diária de trabalho

8 horas

12 horas

\section{Tempo de trabalho na} enfermagem

1 Mês - 1 ano

1 ano - 5 anos

5 anos - 10 anos

10 anos 20 anos

20 anos - 30 anos
7

3

0

0

0

0

0

0

0

7

3

30

23
100

13,1

52,2

30,4

4,4

13,1

21,7

52,2

8,7

4,4

0

Profissionais que atuam em mais de uma instituição de saúde

0

6

60

9

39,1

0

0

3

13,1

0

0

4

17,4

0

0

7

30,4

Sim

3

30

3

13,1

Não

7

70

20

86.9 
Os resultados encontrados neste estudo estão de acordo com o encontrado na literatura, que segundo Moreira 1999 (apud Spindola, 2000), lembra que a enfermagem é caracterizada como uma profissão de mulheres. Esses dados reafirmam que historicamente, as atividades de cuidar dos doentes, com suas características tecnológicas próprias de assistir, higienizar, alimentar, prover os elementos indispensáveis ao bom desenvolvimento do enfermo, seguindo os padrões da divisão social do trabalho, sempre estiveram delegadas à figura da mulher, que representa a maioria como principal provedora de cuidado no ambiente hospitalar (OLER et al., 2005).

Em relação à idade da equipe de enfermagem que participou do estudo, a maioria dos enfermeiros e técnicos de enfermagem está distribuída na faixa etária entre 20 e 40 anos, representando uma população adulto-jovem. Tal situação se deve, segundo Cabanes 1992 (apud LAUTERT et al., 1999):

(...) A considerável redução do número de enfermeiros com idade superior a 40 anos indica que uma grande maioria que atinge essa idade sai do hospital. Este fenômeno pode ser associado à inquietação em que o indivíduo que se encontra nesta faixa etária sente, principalmente quando está no emprego entre 5 e 7 anos. Tal inquietação pode levá-lo a trocar de emprego e, em alguns casos, até de profissão.

Quanto ao número de filhos da população estudada, o maior percentual estava entre os técnicos de enfermagem $(52,2 \%)$ que relataram ter 2 filhos, neste estudo, nenhum dos enfermeiros pesquisados tem filhos, tais dados estão de acordo com a tendência atual na sociedade brasileira (IBGE, 2010). Alguns estudos demonstram um maior percentual de mulheres trabalhadoras com filhos $(88,46 \%)$, o que reafirma os diversos papéis sociais por elas desempenhados e o fato de conciliar todos esses papéis pode representar para algumas trabalhadoras a superação de dificuldades e a clara consciência do seu verdadeiro papel como agente transmissor de conceitos e ideologias. Além disso, o cuidado prestado aos filhos pode ser considerado uma demanda adicional, capaz de gerar estresse e ansiedade em algumas mulheres, mas, por outro lado, a presença de filhos pode favorecer ao bem-estar da mulher trabalhadora (ROCHA, 2008; SPÍNDOLA, 2000).

Em relação à carga horária diária trabalhada, 100\% dos profissionais técnicos de enfermagem entrevistados trabalham 12 horas diárias, perfazendo 48 horas semanais, enquanto que a grande maioria dos enfermeiros $(70 \%)$ trabalha 8 horas diárias, totalizando 40 horas 
semanais, conforme descrito na tabela 2. No entanto, dos 33 profissionais de enfermagem, 6 $(18,2 \%)$ possuem atividade profissional em outra instituição de saúde, justificada, certamente, pelo fato dos profissionais desejarem se estabilizar financeiramente. Stacciarini \& Tróccoli (2001) descrevem que a atual situação econômica e política brasileira, somada à diminuição do valor salarial, redução do mercado de trabalho e conseqüente desemprego, conduzem o enfermeiro a trabalhar em mais de um local, aumentando sua carga horária mensal de trabalho. Segundo dados apresentados na tabela 2, é possível constatar no que se refere ao tempo de trabalho na área da enfermagem que, tanto enfermeiros (60\%) como técnicos de enfermagem $(39,1 \%)$ estão entre 1 a 5 anos atuando na área de enfermagem. Nossos dados estão de acordo com o estudo de Pereira \& Fávero (2001), que também relata que o serviço na área de enfermagem esteve entre 1 e 5 anos.

\section{VARIÁVEIS DOS SUJEITOS DO ESTUDO COM RELAÇÃO AOS FATORES E FONTES ESTRESSORAS}

\section{Enfermeiros}

Dos principais fatores e fontes estressoras questionadas aos enfermeiros e técnicos de enfermagem, serão discutidos apenas aqueles que obtiveram contabilização considerável, ou seja, mais de $50 \%$ dos entrevistados assinalaram a mesma resposta. Outras fontes estressoras questionadas tiveram uma contabilização abaixo do estipulado por este estudo, não sendo, portanto, discutidos aqui.

Para abordagem dos fatores que poderiam ou não gerar estresse no grupo de enfermeiros entrevistados, aplicamos um questionário com 48 questões baseadas em Lautert et al, 1999. Neste estudo apenas 6 questões (relação com subordinado; pouco trabalho: atividade reduzida; imposição da organização (hospitalar) quanto a valores, idéias e métodos que entram em conflito com os seus; sentir-se só face à tomada de decisões importantes; enfrentar as críticas da chefia; reunião com a chefia) foram marcadas por mais da metade dos entrevistados.

Analisando os resultados apresentados na FIGURA 1, dos 10 enfermeiros entrevistados 7 (70\%) e $6(60 \%)$, respectivamente, avaliaram as questões "relação com subordinado" e "pouco trabalho: atividade reduzida" como fatores não geradores de estresse. No que se refere à questão "relação com subordinado", descrito por $70 \%$ dos enfermeiros 
entrevistados, Rezende \& Silva, 2008 afirmam que a relação interpessoal, enfermeiros/técnicos em enfermagem, não é fator estressor, pois nascem durante a convivência no ambiente de trabalho a comunicação, o respeito e a amizade, que ao se relacionarem surge sentimentos positivos que acabam influenciando na realização das atividades e consequentemente na produtividade. Em concordância com esta afirmativa, a pesquisa realizada por Wgner et al., 2009 em um hospital do interior do Rio Grande do Sul, descreve que na relação entre a equipe de enfermagem percebem-se alguns aspectos subjetivos, como conflitos sem maiores conseqüências e interações saudáveis no ambiente de trabalho, favorecendo o crescimento e o fortalecimento grupal pela exigência de vínculos profissionais. Além disso, Ferreira \& Martino, 2006 descrevem que o apoio dos enfermeiros supervisores e o bom relacionamento da equipe diminuem consideravelmente o estresse, enquanto aumentam a satisfação no trabalho. O fator pouco trabalho: atividade reduzida descrito como não gerador de estresse para $60 \%$ dos enfermeiros em estudo estão de acordo com os dados apresentados na pesquisa de Lautert et al.,1999, realizado em um hospital universitário na cidade de Porto Alegre - RS. Neste estudo, as atividades adicionais da chefia de enfermagem não representavam fontes de estresse, o que se justifica, possivelmente, segundo o autor da pesquisa, que o posto de chefia fosse avaliado como atraente e desafiador, mobilizando o indivíduo de tal forma que as fontes estressoras relacionadas ao posto eram interpretadas como positivas, ou que, certamente, os enfermeiros chefes de unidade estivessem dividindo com os colegas do setor as atividades inerentes à chefia, de tal forma que não se sentiam sobrecarregados.

Em relação aos fatores geradores de estresse mais pontuados: reunião com a chefia, enfrentar as critica da chefia, sentir-se só face à tomada de decisões importantes e a imposição da organização (hospitalar) quanto a valores, idéias e métodos que entram em conflito com os seus, alguns autores afirmam que o gerenciamento do serviço de enfermagem não é tarefa simples, mas que a grande dificuldade dos supervisores está na sua relação com a administração do hospital, que muitas vezes alega a segundo plano as necessidades do serviço de enfermagem (JERICÓ 2008). 


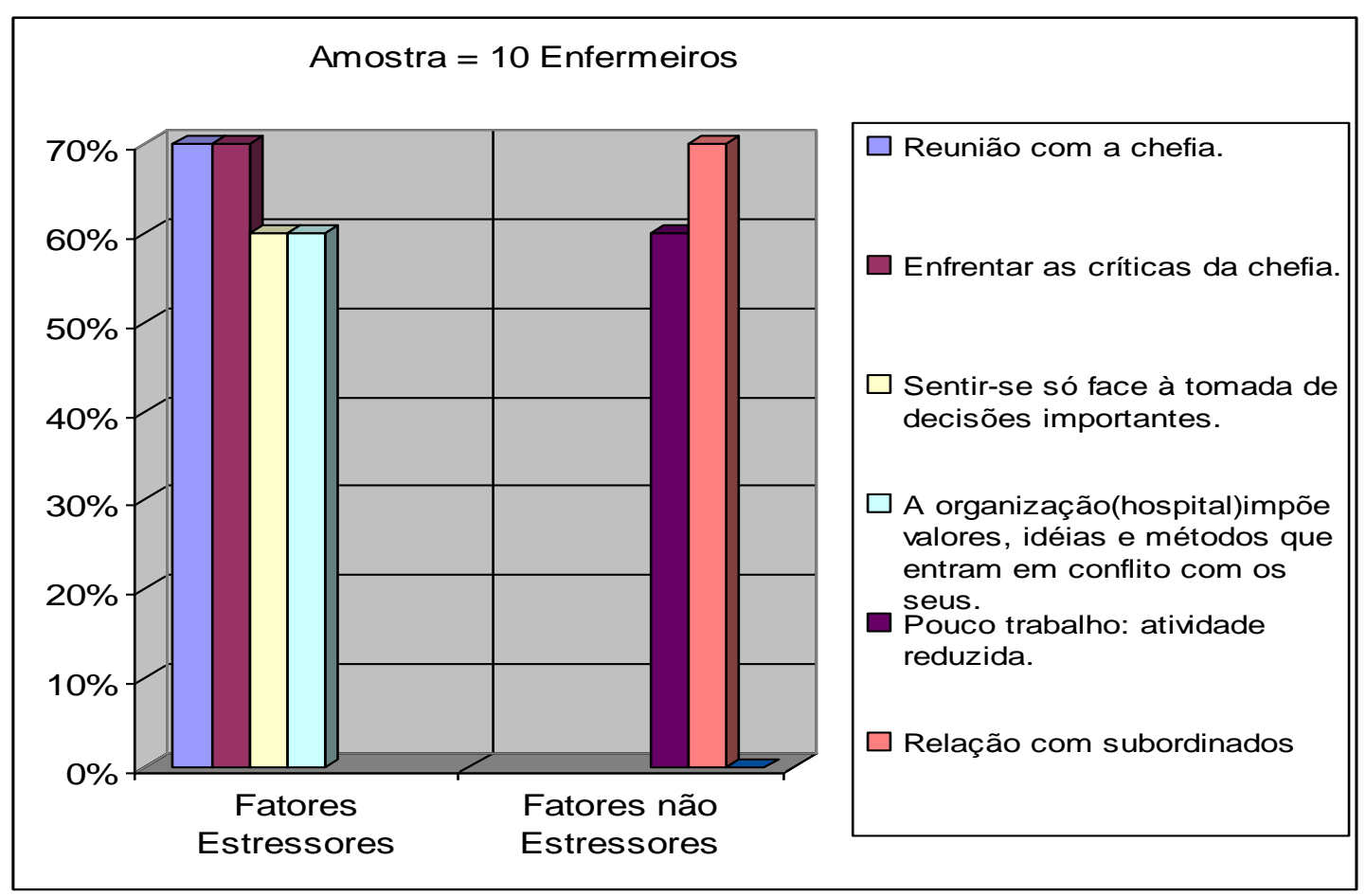

FIGURA 1: Distribuição das principais fontes de estresse dos profissionais enfermeiros num hospital de pequeno porte no interior de Goiás - 2011.

\section{Técnicos de Enfermagem}

Para a abordagem dos fatores e fontes de estresse entre os técnicos de enfermagem, foi aplicado um questionário baseado no Job Diagnostic Survey - Fernandes (1997), em virtude da atuação profissional de enfermeiros e técnicos em enfermagem ser diferentes. Para análise das respostas dadas às 23 questões usadas para investigar os fatores e fontes estressores que poderiam ou não gerar estresse nos técnicos de enfermagem, foi construído o FIGURA 2, que estão dispostos apenas as questões que foram marcadas por mais da metade dos entrevistados, sendo elas: receio de perder o emprego; supervisor que não ajuda a fazer o meu trabalho; enfrentar baixo valor do salário mensal; ter que atender um número grande de pacientes; enfrentar desvalorização profissional pelos pacientes; enfrentar conflitos por parte dos colegas; enfrentar falta de competência eficiência de colegas e enfrentar desvalorização profissional por parte do supervisor.

Em relação aos fatores não geradores de estresse entre os técnicos de enfermagem, receio de perder o emprego foi uma questão pontuada por $78 \%$ dos entrevistados. Uma pesquisa 
conduzida pela Confederação Nacional da Indústria (CNI, 2011) de abrangência nacional relata que $57 \%$ dos entrevistados afirmam não ter medo algum do desemprego. $\mathrm{O}$ autor descreve que o índice reflete o baixo nível de desemprego da economia brasileira. Já Castelhano (2005), descreve que inúmeras pesquisas e estudos que investigam a saúde do trabalhador em seu ambiente de trabalho indicam que o medo do desemprego constitui uma das fontes mais freqüentes de estresse na sociedade moderna.

O fato de os técnicos de enfermagem entrevistados não considerarem a questão “receio de perder o emprego" um fator estressante, pode ser explicado, possivelmente, pela formalização do emprego, que nesses dois últimos anos, cresceu mais que o emprego informal. A formalização do emprego traz mais segurança aos empregados, reduzindo assim o medo do desemprego. Cabe destacar também que, certamente, a maioria dos entrevistados dessa pesquisa faz parte do grupo de trabalhadores ocupantes de emprego público, ou seja, pessoas físicas que prestam serviço ao Estado e às entidades da Administração Indireta, com vínculo empregatício e mediante renumeração paga pelos cofres públicos, sendo certo que essa condição, possivelmente, faz com que o empregado tenha certa segurança e estabilidade, pois somente pode ser despedido por justa causa (AZEVEDO, 2009; BENETTI \& ARAÚJO, 2008).

Verificou-se na FIGURA 2 que os fatores geradores de estresse avaliados pelos técnicos de enfermagem foram enfrentar baixo valor do salário mensal; ter que atender a um número grande de pacientes; enfrentar desvalorização profissional pelos pacientes; enfrentar conflitos por parte dos colegas; enfrentar falta de competência eficiência de colegas e enfrentar desvalorização profissional por parte do supervisor.

A questão "enfrentar baixo valor do salário mensal" foi assinalada por $86,9 \%$ dos sujeitos como uma situação estressante em seu dia-a-dia profissional. Dados de outros autores sustentam essa afirmativa. Cintra 2009 desenvolveu uma pesquisa sobre os fatores de insatisfação no trabalho dos profissionais de enfermagem e seus resultados apontaram que 52 participantes $(84,6 \%)$, estavam insatisfeitos com o salário. Segundo os participantes, a insatisfação salarial justifica-se em função do salário não atender às necessidades pessoais e profissionais, não ser adequado à realidade e o valor ser incompatível às atribuições e carga horária, o que possivelmente, tem como séria conseqüência o aparecimento do estresse.

Quanto à questão "ter que atender a um número grande de pacientes", pode-se inferir que tal situação certamente contribui para o surgimento de estresse. Os dados apresentados 
na FIGURA 2 indicam que 73,9\% consideram esta situação estressante em seu dia-a-dia profissional. De acordo com o estudo realizado por Tanos et al., 2000, com a equipe de enfermagem em uma clínica de um hospital público universitário, os sujeitos da referida pesquisa, frequentemente, relatam que existe grande sobrecarga de trabalho, tendo a percepção de que o quadro de pessoal da unidade é menor do que o necessário. Rocha (2008) afirma que a sobrecarga de trabalho é um fator importante para diminuir o tempo de assistência de enfermagem. Em vista disso, é possível que esse tempo diminuto comprometa a qualidade da assistência e, consequentemente, repercuta na satisfação profissional. A esse respeito, Batista et al ., 2005, relatam que as condições de trabalho, carga horária coerente com o número de funcionários e salários dignos estão entre os fatores importantes de satisfação profissional na atividade da equipe de enfermagem.

É importante destacar que neste estudo a questão: enfrentar desvalorização profissional pelos pacientes, quando analisamos os fatores e as fontes estressoras (FIGURA 2). Cerca de $70 \%$ dos sujeitos entrevistados em nossa pesquisa assinalaram essa questão. O sentimento de desvalorização referido pelos técnicos de enfermagem neste estudo, está acima dos percentuais (63\%) obtidos no estudo de Montanholi et al ., 2006, realizado com a equipe de enfermagem que trabalham no Hospital Escola da Faculdade de Medicina do Triângulo Mineiro. O referido autor afirma que a aceitação pelos pacientes é uma questão muito relevante para o profissional, que o relacionamento com os pacientes é um fator protetor contra o estresse e que o reconhecimento profissional gera satisfação no trabalho.

Em análise ao resultado do questionamento: "enfrentar conflitos por parte dos colegas" pontuada como fator estressor por $65 \%$ dos nossos participantes podemos observar que outros estudos sobre os conflitos entre a equipe de enfermagem, mostram que numa situação de pressão, os profissionais, muitas vezes, não conseguem manter o controle emocional, manifestando agressividade com os colegas causada, certamente pelo estresse. Problemas pessoais ou características da personalidade também podem dificultar o relacionamento entre os profissionais da equipe. Dentre os motivos que interferem no surgimento de conflitos entre a equipe de enfermagem, destacam-se atitudes individualistas acompanhado de comportamento egoísta e competitivo, os problemas pessoais, as diferenças individuais, a falta de confiança, a comunicação e as relações de poder (TANAKA, 2001). Neste contexto, podemos relacionar ainda os resultados deste fator estressor com as escalas de folgas mensais, férias, feriados, finais de 
semana e marcação de férias. Outros conflitos enfrentados estão envolvidos com o turno de trabalho e com as escalas por clínicas, muitas vezes levando os profissionais à insatisfação.

Conforme se evidencia na FIGURA 2, 60\% dos participantes consideram a questão "enfrentar desvalorização profissional por parte do supervisor" uma situação estressora em seu ambiente laboral. Para Costenaro \& Stecca, 2004 as qualidades e virtudes individuais dos funcionários destacadas pelos supervisores e/ou gerentes contribuem para que os indivíduos sintam-se úteis e motivados, o que se torna um importante fator de crescimento e sucesso organizacional. Os autores relatam ainda que, os supervisores devem incentivar os trabalhadores ao acerto e ajudá-los nas dificuldades, contribuindo assim, para harmonizar o ambiente de trabalho, bem como enaltecer o valor de cada funcionário.

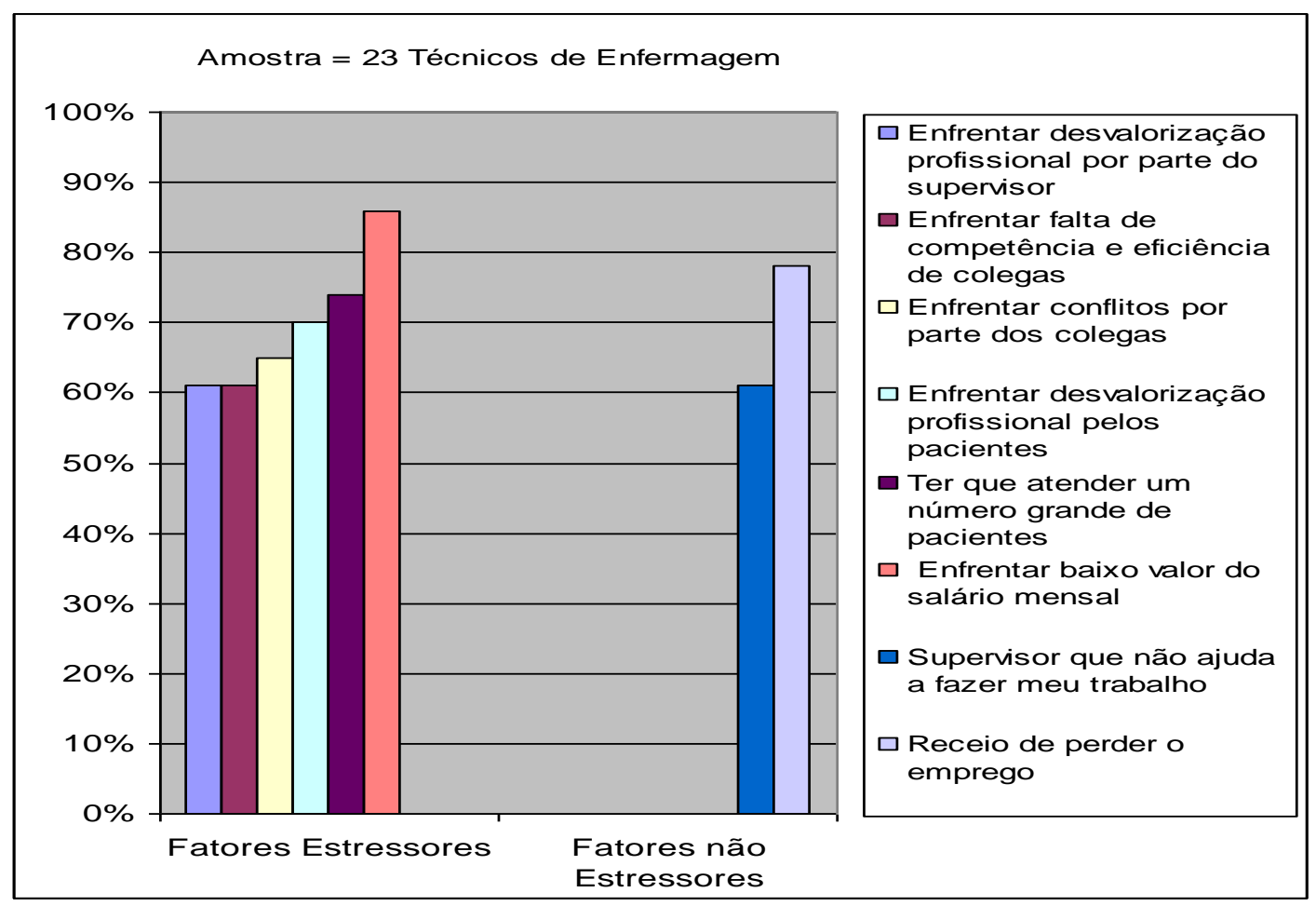

FIGURA 2: Distribuição das principais fontes de estresse dos profissionais Técnicos de Enfermagem num hospital de pequeno porte no interior de Goiás - 2011.

\author{
VARIÁVEIS DOS SUJEITOS DO ESTUDO COM RELAÇÃO AOS FATORES QUE \\ INVESTIGAM OS SENTIMENTOS DOS PROFISSIONAIS DE ENFERMAGEM EM \\ RELAÇÃO A ALGUMAS CONDIÇÕES DE TRABALHO
}


As questões que investigam os sentimentos dos profissionais de enfermagem em relação a algumas condições de trabalho foram baseadas no questionário de Lautert et al., 1999. As principais variáveis assinaladas pelos participantes foram: Você deve freqüentemente fazer um esforço para ir trabalhar?; Você está satisfeito (a) com seu atual trabalho?; Você pensa em mudar de posição no local de trabalho?; É bem humorado durante a execução das atividades?; Aceita com facilidade as mudanças feitas pela chefia. Para a análise destas variáveis, assim como para outras variáveis discutidas neste estudo, iremos considerar apenas aquelas que obtiveram contabilização acima de 50\% nas respostas dos entrevistados (FIGURA 3).

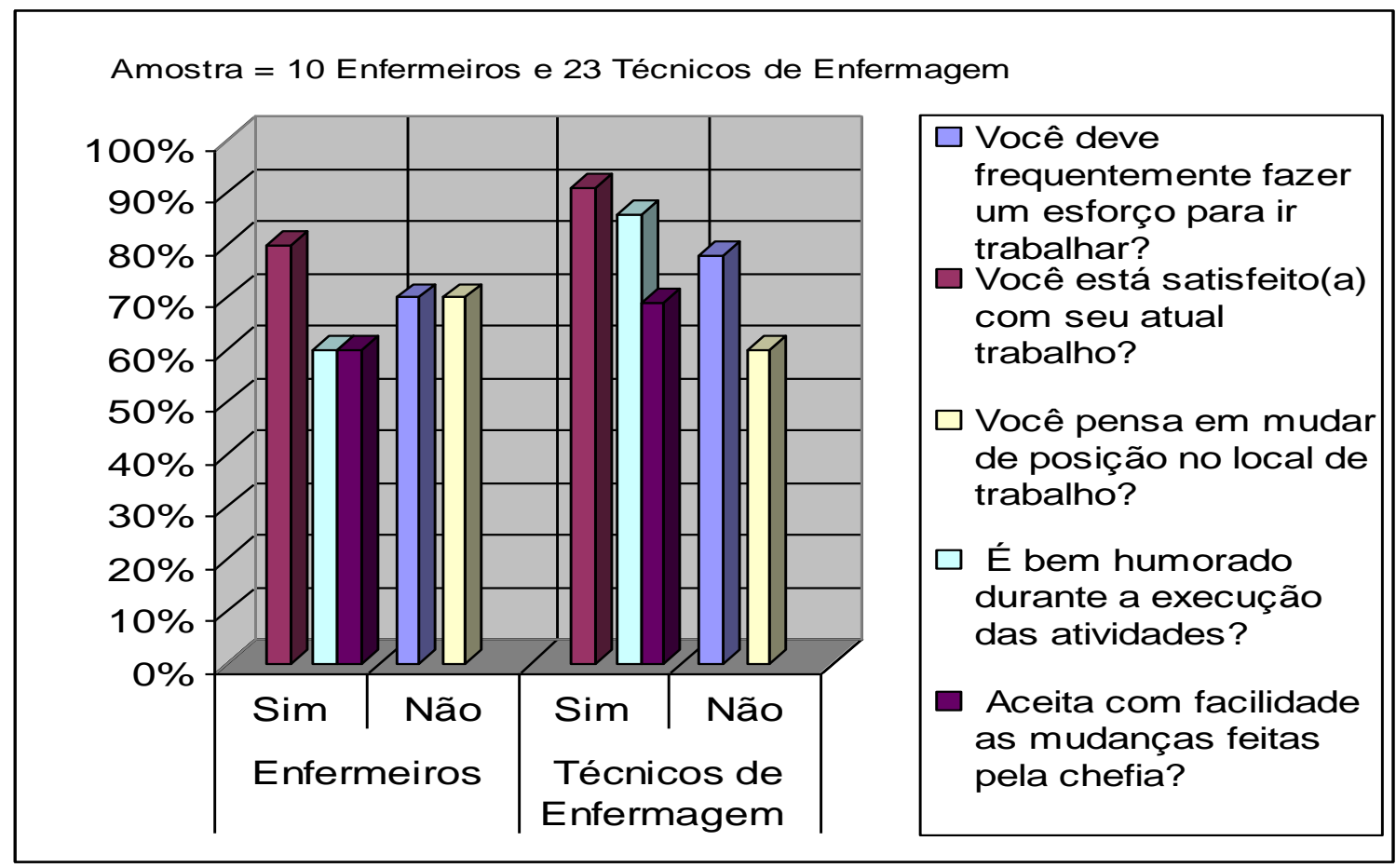

\section{FIGURA 3: Distribuição dos principais fatores que investigam os sentimentos dos} profissionais de enfermagem em relação a algumas condições de trabalho num hospital de pequeno porte no interior de Goiás - 2011.

Convém destacar que a questão "você está satisfeito (a) com seu atual trabalho", foi à única variável que teve maior número de citações entre os sujeitos da pesquisa (80\% entre enfermeiros e 91,3\% entre técnicos de enfermagem). Isto confirma que os fatores referentes às condições laborais referem-se ao conteúdo do cargo, às tarefas e aos deveres relacionados com o 
cargo em si, produzindo efeitos duradouros de satisfação e aumento de produtividade em nível de excelência (PEREIRA \& FÁVERO, 2001).

\section{VARIÁVEIS DOS SUJEITOS DO ESTUDO COM RELAÇÃO À INCIDÊNCIA DE ESTRESSE E SINTOMATOLOGIA MAIS FREQUENTE}

Para avaliar os profissionais da equipe de enfermagem, utilizamos o Inventário de Sintomas de Stress - I.S.S proposto por Lipp \& Guevara, 1994. Tal instrumento permite diagnosticar a presença ou não de estresse, a fase em que o indivíduo se encontra (fase de alerta, fase de resisência ou quase-fase exaustão e fase de exaustão) e ainda a sintomatologia característica dos quadros estresse. Na amostra global $(n=33), 21(63,6 \%)$ profissionais não apresentam sintomas de estresse segundo o I.S.S, não atingindo dessa forma, nem mesmo a fase de alerta (que inclui sete sintomas ou mais, nas últimas 24 horas). No entanto, $12(36,4 \%)$ dos participantes apresentam sintomas de estresse (FIGURA 4). Destes, 10 (83,3\%) apresentaram a fase de resistência e apenas $2(16,7 \%)$ encontraram-se na fase de exaustão, conforme demonstra a FIGURA 5.

Este estudo registra um percentual relativamente baixo de sintomas de estresse nos profissionais de enfermagem pesquisados $(36,4 \%)$, quando comparado com outras pesquisas. Em estudos semelhantes realizados em instituições onde as condições do ambiente laboral são sabidamente estressantes como UTIs e hospitais públicos, deparamo-nos com percentuais de sintomas de estresse mais elevados. No estudo de Molina \& Guimarães (2007), 66\% dos profissionais de enfermagem apresentaram sintomas de estresse. Um percentual de 78,4\% foi encontrado na pesquisa de Panizzon et al., 2008, e 82,4\% dos profissionais de enfermagem estudados por Schamidt et al., 2009, apresentaram sintomatologia característica de estresse. 


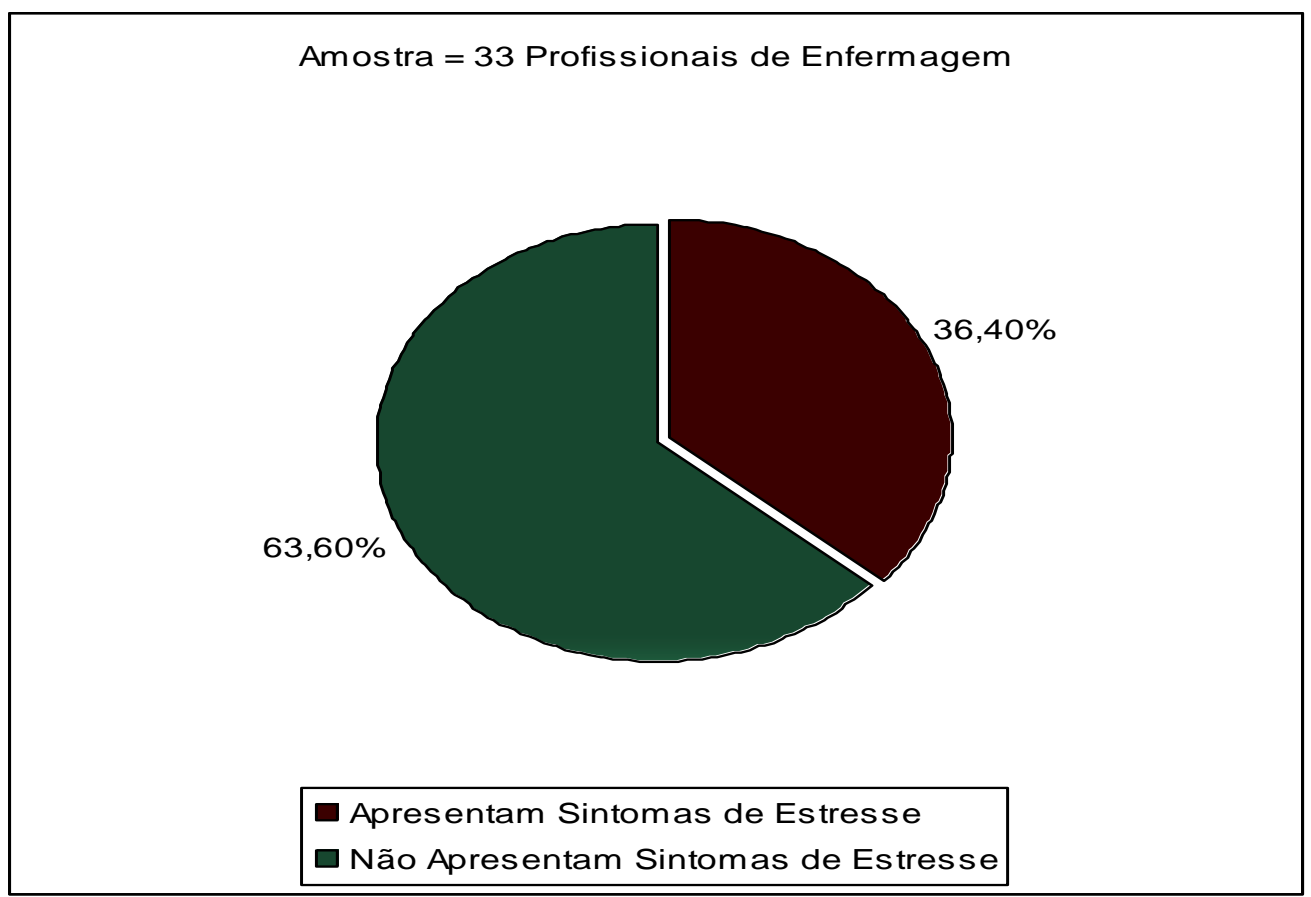

FIGURA 4: Sintomas de estresse (LIPP \& GUEVARA, 1994) identificados nos profissionais de enfermagem em um hospital de pequeno porte no interior de Goiás 2011.

Acredita-se que o percentual pouco elevado de sintomatologia de estresse nos profissionais de enfermagem registrado neste estudo, certamente ocorreu em virtude de uma resposta de adaptação e equilíbrio homeostático da equipe de enfermagem no processo de estresse diante do estressor. Lazaus (Apud Costa et al., 2003) afirma que os esforços cognitivos e de enfrentamento (mecanismo de coping) tornam os indivíduos capazes de identificar, administrar, avaliar e manter o equilíbrio em resposta ao estressor. Embora a maioria das pesquisas sobre o tema aborde alto índice de estresse laboral entre profissionais de diversas áreas, vale lembrar que o estresse é um processo dinâmico e, por isso, tanto pode ser agravado quanto revertido, dependendo da forma de enfrentamento utilizado pelo indivíduo. De acordo com esta afirmativa Silva (2007), relata que o ambiente externo é responsável por diferentes graus de estresse, mas existem características relacionadas também às atividades do profissional. Diante dessa afirmativa, podemos sugerir que, em relação ao ambiente externo, o fato dos profissionais de enfermagem entrevistados neste estudo não apresentar alto percentual de estresse, se dá provavelmente em virtude de viverem em uma cidade com aproximadamente 18.000 habitantes (IBGE, 2010), onde os índices de violência são baixos, a convivência com as pessoas é mais 
acolhedora, o custo de vida é menos dispendioso e o trânsito é tranqüilo, ou seja, o ambiente é favorável ao bem estar do profissional. Em relação ao ambiente de trabalho, deve-se considerar o perfil da unidade hospitalar em estudo. Trata-se de uma instituição com menos de 40 leitos e um atendimento diário de aproximadamente 150 pacientes (comunicação pessoal). Além disso, o hospital apresenta baixa resolubilidade, ou seja, não dá seguimento a diversos tratamentos, dessa forma, as atividades diárias são menos desgastantes, podendo ser dividas entre os profissionais de forma a não ocorrer sobrecarga de trabalho, tornando a atividade laboral da equipe menos estressante.

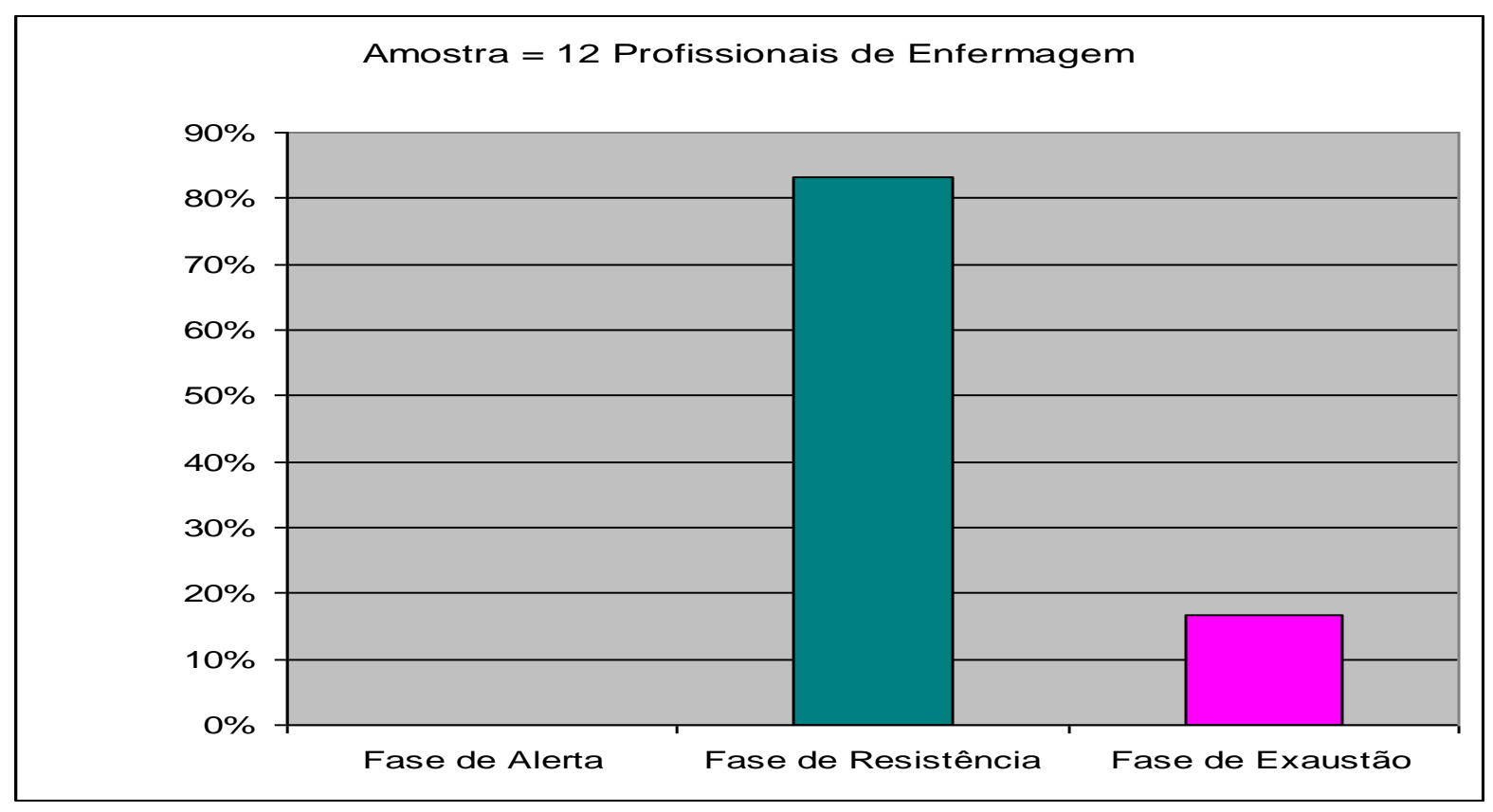

FIGURA 5: Fases de estresse (LIPP \& GUEVARA, 1994) identificadas nos profissionais de enfermagem em um hospital de pequeno porte no interior de Goiás 2011.

A FIGURA 6 mostra a ocorrência dos sintomas físicos e psicológicos de estresse referentes aos profissionais da equipe de enfermagem pesquisados $(n=33)$. Para avaliação destes sintomas, utilizamos o Quadro 2 do I.S.S (Lipp \& Guevara, 1994). Observou-se nesses dados que houve uma predominância de sintomas físicos, sendo os mais assinalados problemas com a memória (30,3\%); sensação de desgaste físico constante (54,5\%); mudança de apetite (51,5\%) e cansaço constante (54,5\%). Segundo Camelo (2004), o cansaço constante na equipe de enfermagem é característico da síndrome da fadiga, definida como um “desgaste de energia física 
ou mental, que pode ser recuperada por meio do repouso, alimentação ou orientação clínica específica". A fadiga poderá ter repercussões sobre vários sistemas do organismo, provocando múltiplas alterações de funções, que conduzem a uma diminuição do desempenho no trabalho em graus variáveis e a uma série de distúrbios psicológicos, familiares e sociais. Já o sintoma psicológico mais presente na equipe de enfermagem foi pensar constantemente em um só assunto (39,4\%), como é um sintoma subjetivo, acreditamos que este possa refletir tanto situações profissionais no âmbito hospitalar, quanto problemas pessoais deste profissional, de forma que ambos possam interferir no emocional destes indivíduos.

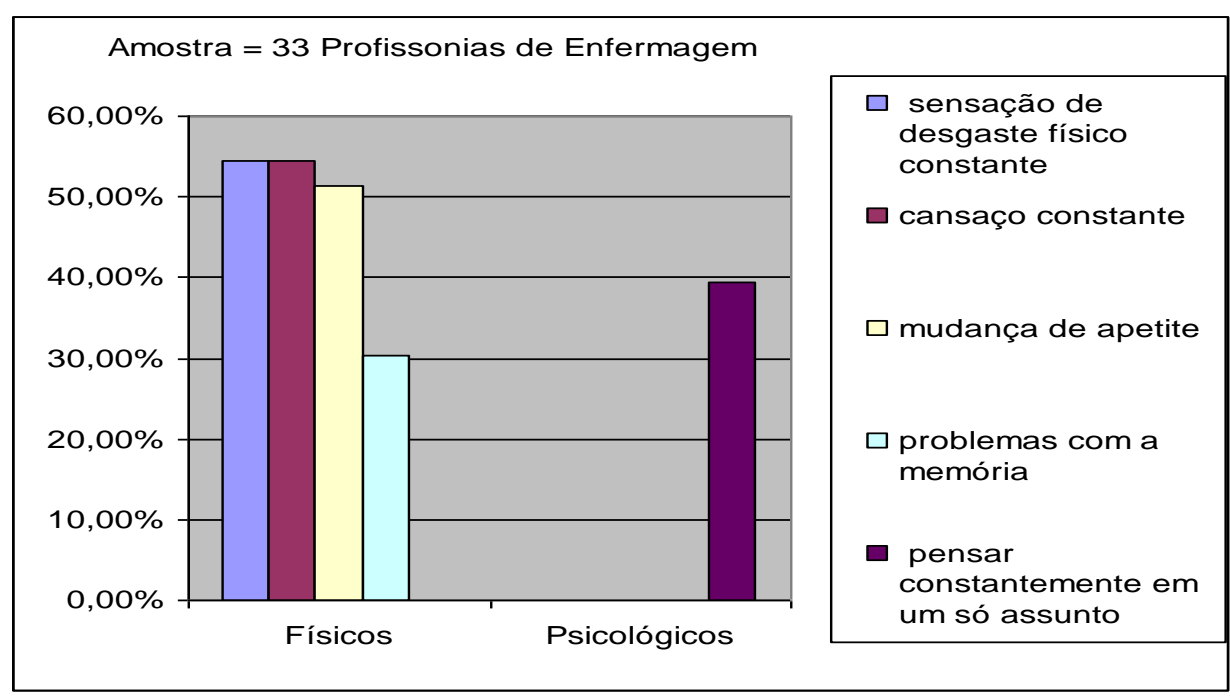

FIGURA 6: Ocorrência de sintomas físicos e psicológicos de estresse (LIPP \& GUEVARA, 1994) referentes aos profissionais da equipe de enfermagem em um hospital de pequeno porte no interior de Goiás - 2011.

\section{CONCLUSÃO}

A proposta de investigar a incidência de estresse na equipe de enfermagem de um hospital de pequeno porte no interior de Goiás nos permitiu constatar um baixo percentual de estresse $(36,4 \%)$ nesta população. A pesquisa revelou que em 63,6\% dos participantes não houve ocorrência de estresse, fato esse que se deve provavelmente ao conjunto de situações favoráveis ao bem estar do profissional, tanto no ambiente externo quanto no próprio ambiente de trabalho. 
Ao verificarmos as principais fontes e fatores geradores de estresse na equipe de enfermagem, avaliamos separadamente enfermeiros e técnicos de enfermagem em virtude de executarem ações diferenciadas no ambiente hospitalar. Inúmeros fatores e fontes foram pontuados pelos entrevistados, os enfermeiros foram analisados de acordo com o questionário de Lautert et al, 1999 e os técnicos de enfermagem de acordo com o questionário baseado no Job Diagnostic Survey - Fernandes 1997. Diante dos resultados podemos concluir que apesar da equipe de enfermagem conviver com inúmeros fatores e fontes estressoras, a maioria consegue lidar com estes de maneira adequada, fazendo com que estes não interfiram de maneira significativa na sua vida profissional e pessoal. Assim, esta equipe se mantém saudável, presta uma boa assistência ao paciente e contribui com a imagem positiva da instituição frente à população.

Ao identificar os principais sintomas de estresse descritos pelos entrevistados neste estudo, foi possível observar que houve uma predominância de sintomas físicos, sendo o mais frequente o cansaço constante, verificado em 54,5\% dos sujeitos pesquisados. Sabe-se que tal sintoma pode evoluir para a síndrome da fadiga, que provoca múltiplas alterações de funções orgânicas e que pode conduzir a uma diminuição do desempenho no trabalho e a uma série de distúrbios psicológicos, familiares e sociais.

É importante ressaltar que outras investigações se fazem necessárias para aprofundarmos em algumas questões relativas ao estresse na equipe de enfermagem. Outro ponto a destacar seria corrigir a deficiência do número pequeno de amostra neste estudo.

\section{CONSIDERAÇÕES FINAIS}

É sabido que a manisfestação de estresse aliado a fatores da cultura organizacional vigente levam o trabalhador a suprimir suas necessidades básicas para o desempenho da tarefa por ele a ser executada, culminando em um processo gradativo de adoecimento que, por conseguinte, afeta sua qualidade de vida. Percebe-se, portanto, que é de grande importância manter o baixo índice de estresse entre a equipe estudada, portanto, sugerimos a implantação de um espaço para exercício físico; de algum tipo de meditação como ioga ou tempo disponível para discussão e reflexão que visem o esclarecimento do estresse e suas possíveis conseqüências na vida profissional, pessoal e social de cada indivíduo. Acredita-se que tais sugestões são 
imprescindíveis para evitar o adoecimento mental da equipe estudada e garantir a qualidade da assistência ao paciente.

\section{REFERÊNCIAS}

ALVES G.J, PALERMO-NETO J.; Neuroimunomodulação: sobre o diálogo entre os sistemas nervoso e imune. Rev Bras Psiquiatr. 2007; 29(4):363-369. Disponível em: http://www.scielo.br/pdf/rbp/v29n4/a13v29n4.pdf

AZEVEDO, M. S. Nota técnica. O índice do Medo do Desemprego. Ago. 2009. Disponível em: http://www.ipea.gov.br/sites/000/2/boletim_mercado_de_trabalho/mt40/03_NT_indice.pdf.

Acesso: 29/11.

BAUER, M.E. Estresse: como ele abala as defesas do organismo. Ci Hoje 2002; 3(179): 20-5.

BATISTA K. M.; BIANCHI E. R. F.; Estresse do enfermeiro em unidade de emergência. Rev. Latino-am Enfermagem 2006 julho-agosto; 14(4): 534-9.

BATEMAN, T. S.; STRASSER, S. A longitudinal analysis of the antecedents of organizational commitment. Academy of Management Journal, n. 27, p. 95-112, 2000. Disponível: http://scielo.isciii.es/pdf/eg/n18/pt_revision1.pdf.

BORGES, L.O; ARGOLO, J.C.T; PEREIRA, A.L.S; MACHADO, E.A.P; SILVA, W.S. A síndrome de Burnout e os valores organizacionais: um estudo comparativo em hospitaisuniversitários.Rev.Psicol:Refle.Crit.2002;15(1):189-2002

http://www.psicologia.ufrgs.br/departamentos/depto.

BAUER M. E. Estresse, como ele abala as defesas do corpo? Instituto de Pesquisas Biomédicas e Faculdade de Biociências, Pontifícia Universidade Católica do Rio Grande do Sul. CIÊNCIA HOJE • vol. 30 • no 179 M E D I C I N A, Jan./Fev. de 2002. Disponível em: http://www.dbm.ufpb.br/ marques/Artigos/Estresse.pdf

BALLONE, G. J. Estresse e Trabalho. Disponível http//www.psiqweb.med.br. Acessado em: 11 de Maio 2011.

BATISTA, A. A.V, et al. Fatores de motivação e insatisfação no trabalho do enfermeiro. Rev Esc Enferm USP, v, 39, n. 1, p. 85-91, 2005.

BENETTI, L. T; ARAÚJO, A. F. As relações de trabalho do servidor público: regime estatutário x regime celetista Revista Científica Eletrônica de Ciências Contábeis. Ano VI - Número 11 Maio de 2008 - Periódicos Semestral.

CNI - Publicação trimestral da Confederação Nacional da Indústria. Medo do desemprego é o menor da série. Ano 3 Número 3, setembro de 2011 www.cni.org.br 
CNS - CONSELHO NACIONAL DE SAÚDE. Resolução n. 196, de 10 de outubro de 1996. Diretrizes e normas regulamentadoras de pesquisa envolvendo seres humanos. Diário Oficial da União. Brasília. Out. p.21082-85.

COSTA, J.R.A.; LIMA, J.V. de; ALMEIDA, P.C. de A. Stress no trabalho do enfermeiro. Revista da Escola de Enfermagem da Universidade de São Paulo -

USP. 2003. Disponível em: http://www.scielo.br/pdf/reeusp/v37n3/08.pdf

CARMELO, S.H.H; ANGERAMI, E.L.S. Sintomas de estresse nos trabalhadores atuantes em cinco núcleos de saúde da família. Rev. Latino Ame. Enfermagem. 2004; 12(1): 14-21.

CASTELHANO, L. M. O medo do desemprego e a(s) nova(s) organizações de trabalho. Psicologia \& Sociedade; 17 (1): 17-28; jan/abr.2005. Disponível em: http://www.scielo.br/pdf/psoc/v17n1/a03v17n1.pdf. Acesso 28/11.

COFEN - Conselho Federal de Enfermagem. Dados estatitiscos sobre a composição e distribuição da força de trabalho de enfermagem, 2011. Disponívem em http://site.portalcofen.gov.br/node/4254.

COFEN - Conselho Federal de enfermagem. Resolução $\mathrm{N}^{\circ} 189 / 96$ Normatiza em âmbito Nacional a obrigatoriedade de haver Enfermeiro em todas as unidades de serviço onde são desenvolvidas ações de Enfermagem durante todo o período de funcionamento da instituição de saúde.

CABUSSÚ, M.A. S. T. Dislexia e estresse: implicações neuropsicológicas e psicopedagógicas Rev. psicopedag. vol.26 nº 81. São Paulo 2009.

CINTRA, H. D. E et al Fatores que prejudicam o trabalho do enfermeiro que atua em hospital. Seminário Internacional “Experiências de Agendas 21: Os desafios do nosso tempo". 27, 28 e 29 de Nov. 2009. Ponta Grossa - PR Brasil. Disponível em: http://eventos.uepg.br/seminariointernacional/agenda21 parana/trabalho_cientifico/TrabalhoCienti fico022.pdf

COSTENARO, A. C; STECCA, J. P. Motivação profissional: Um indicador de qualidade de vida. Revista Eletrônica de Contabilidade VOLUME I. N.1 SET-NOV/2004. Disponível em: http://w3.ufsm.br/revistacontabeis/anterior/artigos/vIn01/a13vIn01.pdf

Acesso dia 21/11.

FERREIRA, L.R.C; De MARTINO, M.M.F. O estresse do enfermeiro: análise das Publicações sobre o tema. Rev. Ciênc. Méd., Campinas, 15(3): 241-248 maio/jun., 2006.

FERNANDES, S.R.P. (1997). Tecnologia informática e saúde psíquica: estudo da associação entre dimensões psicossociais do trabalho e sintomas psicológicos em duas empresas. Tese de Doutorado, Instituto de Saúde Coletiva, Universidade Federal da Bahia. 
IBGE - Instituto Brasileiro de Geografia e Estatística. Brasil em síntese: taxas de fecundidade total: 1990-2010. Disponível em: http://www.ibge.gov.br/brasil_em_sintese/

Id. Cidades. http://www.ibge.gov.br/cidadesat/topwindow.htm

JERICÓ M. C et al Estrutura organizacional do serviço de enfermagem: reflexões sobre a influencia do poder e da cultura organizacional. Rev Esc Enfem USP.2008.

LAUTERT L et al; O estresse na atividade gerencial do enfermeiro Rev Panam Salud Publica/Pan Am J Public Health 6(6), 1999. Disponível em: http://www.scielosp.org/pdf/rpsp/v6n6/0968

LIPP, M.E.N. Manual do inventário de sintomas do stress para adultos de Lipp (ISSL). São Paulo: Casa do Psicólogo; 2000.

LIPP, M. E. N. \& GUEVARA, A J. H. Validação empírica do inventário de sintomas de stress (ISS). Estudos de Psicologia, 3 (11),43-9.1994.

LEITE, P. C.; SILVA, A; MERIGHI, M. A. B. A mulher trabalhadora de Enfermagem e os distúrbios osteomusculares relacionados ao trabalho. Revista da Escola de Enfermagem da USP, São Paulo, v.41, n.2, p.287-291, junho 2007. Disponível em: http://www.scielo.br/scielo.

LENTINE, E. C. et al. Estresse de Profissionais de Saúde das Unidades Básicas do Município de Londrina. Terra e Cultura, ANO XIX, No 37, Jun. Dez. 2003. Disponível:http://web.unifil.br/docs/revista_eletronica/terra_cultura/37/Terra\%Cultura_37-10.pdf

LOPES, M J M; SCHUCK, J S. A Enfermagem e a Saúde dos Trabalhadores. 2a ed. Goiânia $\mathrm{AB}, 2001$.

MONTANHOLI, L.L., TAVARES, D.M.S., OLIVEIRA, G.R.; Estresse: fatores de risco no trabalho do enfermeiro hospitalar. Rev Bras Enferm 2006 set-out; 59(5): 661-5. Disponível: http://www.scielo.br/pdf/reben/v59n5/v59n5a13.pdf.

MENZANI, G., BIANCHI, E.R.F. Stress dos enfermeiros de pronto socorro dos hospitais brasileiros.Rev.Eletr.Enf.2009;11(2):32733.http://www.fen.ufg.br/revista/v11/n2/v11n2a13.

MARZIALE, M. H. P; RODRIGUES, C M. A produção científica sobre os acidentes de trabalho com material perfuro cortante entre trabalhadores de Enfermagem art.2. Revista latino Americana de Enfermagem, Ribeirão Preto,v.10. n.4, jul./ago.2002.

MURTA, S.G. TRÓCCOLI,B.T. Avaliação de intervenção em estresse ocupacional. Rev. Psicol: Teoria Pesq.2004;20(1):3947.http://www.psicologia.ufrgs.br/departamentos/.

MOLINA; T.C.; GUIMARÃES, C.P.A. Estudo comparativo sobre estresse ocupacional na Equipe de enfermagem: pediatria $\mathrm{x}$ uti neopediátrica. Fevereiro/2007 
OLER. F. G. et al; Qualidade de vida da equipe de enfermagem do centro Cirúrgico. Arq Ciênc Saúde 2005 abr-jun;12(2):102-10

POLIT, D.F; HUNGLER, B.P.; Fundamentos de pesquisa em enfermagem. 3a ed. Porto Alegre: Artes Médicas; 1995.

PEREIRA M.C.A., FÁVERO N. A motivação no trabalho da equipe de enfermagem. Rev Latinoam $\quad$ Enfermagem 2001 jul. 9(4):7-12. Disponível em http://www.scielo.br/pdf/rlae/v9n4/11476.pdf

PANIZZON; C. LUZ ; A.M.H, FENSTERSEIFER; L.M. Estresse da equipe de enfermagem de emergência clínica. Rev Gaúcha Enferm., Porto Alegre (RS) 2008 set;29(3):391-9.

REZENDE, T; SILVA, R M. A qualidade de vida no trabalho dos profissionais da área de enfermagem: um estudo a partir do modelo teórico de Hackman \& Oldhan. Estudos e

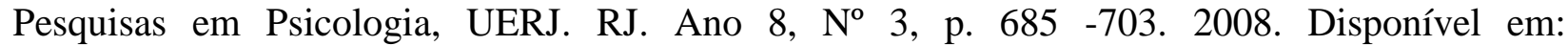
http://www.revispsi.uerj.br/v8n3/artigos/pdf/v8n3a10.pdf. Acesso 16/11.

RIBEIRO, E. J. G; SHIMIZU, H. E. Acidentes de trabalho com trabalhadores de Enfermagem. Revista Brasileira de Enfermagem REBEN, Rio de janeiro, v.60, n.5, p.535-540, set/out 2007. Disponível em: http://www.scielo.br/scielo.

ROSSETTI M. O et al.;O inventário de sintomas de stress para adultos de lipp (ISSL) em servidores da polícia federal de São Paulo. Rev. bras.ter. cogn. v.4 n.2 Rio de Janeiro dez. 2008.

ROCHA, M. C. P. Estresse e o ciclo de vigília-sono do enfermeiro que atua em diferentes setores do ambiente hospitalar. 2008. 215f. Dissertação (Mestrado) - Faculdade de Ciências Médicas. Universidade Estadual de Campinas, Campinas, 2008. Disponível em: http://www.bibliotecadigital.unicamp.br/document/.

SPÍNDOLA T. Mulher, mãe e... Trabalhadora de enfermagem. Rev Esc Enferm USP 2000; 34(4):354-61.

STACCIARINI, J.M.R, TRÓCCOLI, B.T. O estresse na atividade ocupacional do enfermeiro. Rev. Latino Ame. Enfermagem. 2001; 9(2): 17-25.

SILVA J.L.L; Estresse e transtornos mentais comuns em trabalhadores de enfermagem. [dissertação]. Rio de Janeiro (RJ): Escola de Enfermagem Alfredo Pinto, Universidade Federal do Estado do Rio de Janeiro; 2007.

SILVA, F.P.P; Bournot: Um desafio à saúde do trabalhador. Psi -revista de psicologia social e institucional.jun/2000;2(1).Disponível em: http://www2.uel.br/ccb/psicologia/.

SILVA A. A et al Riscos Ocupacionais a que Estão Expostos os Profissionais de Enfermagem no Ambiente Hospitalar e Fatores que Favorecem a sua Ocorrência. Rev. Objetiva. No 4; 2008. Disponível em: http://www.proac.uff.br/biosseguranca. 
SCHMIDT D. R. C. et al; Estresse ocupacional entre profissionais de enfermagem do bloco cirúrgico. Artigo Original. Red de Revistas Científicas de América Latina Texto \& Contexto Enferm, Florianópolis, 2009 Abr-Jun; 18(2): 330-7.

TANOS, M.A.A. et al. Dimensionamento de pessoal de enfermagem em uma unidade especializada em transplante de fígado: comparação do real com o preconizado. Rev.Esc.Enf. USP. V.34, n.4, p. 376-82, dez. 2000.

TANAKA, L.H. Compreendendo o relacionamento interpessoal no contexto do trabalho: visão dos enfermairos-chefes de um hospital de ensino. Escola de

Enfermagem, Univ. De São Paulo, 2001.

WAGNER, L.R. et al. Relações Interpessoais No Trabalho: Percepção de Técnicos e Auxiliares de Enfermagem. Cogitare Enferm 2009 Jan/Mar; 14(1):107-113. 